\title{
Echocardiographic assessment of Left Ventricular Dyssynchrony in Hypertensive Patients with Normal Systolic Function
}

\author{
MarwaTareq Mohammed, M.B.Ch.B *, HusamThaaban Al-Zuhairi, F.I.B.M.S **, Ali Mohammed Al Yassin C.A.B.M., F.R.C.P \\ $* * *$
}

\begin{abstract}
Background: Normal Left Ventricular systolic function is present in nearly $50 \%$ of patients with congestive heart failure, the majority of such patients have systemic hypertension. Recent studies have demonstrated Left Ventricular dyssynchrony among patients with heart failure and normal systolic function. The co-existence between Left Ventricular dyssynchrony and hypertension with normal systolic function (with no clinical evidence of heart failure) is less well understood.
\end{abstract}

Objective:

To assess the Left Ventricular dyssynchrony among hypertensive patients with normal systolic function by using Tissue doppler imaging.To find out the associations between the LV dyssynchrony and other global echocardiographic findings like (LA volume index, LVmassindex , LV sephericity and LV filling pressure E/E')

Type of the study: Prospective case- control study

Methods: The study conducted in Baghdad Teaching Hospital from $1^{\text {st }}$ of June 2015 to 30th of May 2016 .Study included two groups of people, 40 patients, age_ matched healthy (control) group (group1) and 60 patients with established hypertension (group 2). A Complete 2-D and TDI echocardiography studies with simultaneous ECG were • performed for all patients. Examination involved LV septal and posterior wall thicknesses, internal dimensions, left • atrial size, ejection fraction and tissue doppler derived waves velocities E', E/E.' Dyssynchrony was determined by • measuring T-P max ( the maximal time difference from the onset of QRS to peak systolic velocity on TDI between any opposing LV wall in 3 apical views).

Results: The study included 40 age -matched control people, 27 males $(67.5 \%)$ and 13 females (32.5\%) with a male to female ratio was $1.8: 1$, ranging from (42.4-58y) with mean age was (50.2 $\pm 7.8 \mathrm{y})$ (group 1) and 60 hypertensive patients, 38 males $(63.3 \%)$ and 22 females $(36.7 \%)$ with a male to female ratio was $1.7: 1$, ranging from (48.5- 66.5y) with mean age of (57.5 $\pm 9.0 \mathrm{y})$ (group 2) . Left Ventricular dyssynchrony was identified in 20 of 60 patients $(33.3 \%)$ .Dyssynchrony had no significant association with age and BSA. But it was significantly associated with LA volume index $(r=0.61, \mathrm{p}=0.001)$, LV mass index $(r=0.52, \mathrm{p}=0.001)$, LV sphericity index $(r=0.5, p=0.003)$ ) and LV filling pressure $(r=0.6$, $p$ value $=0.001)$. Dyssynchrony had significant negative correlation with $\left(E^{\prime}\right)$ velocity $(r=-0.7, P$ $=0.001$ ).

Conclusion: Left Ventricular dyssynchrony is frequent among hypertensive patients with normal LV systolic function .The Left Ventricular dyssynchrony is significantly related to LA volume, LV mass, LV sphericity and LV filling pressure.

Key words: LV, Tissue Doppler, LA, Hypertension.

\section{Al-Kindy College Medical Journal 2018: Vol. 14 No.1 Page: 58-63}

*Pediatrics cardiology. Ibn Al-Nafis cardiovascular teaching hospital

** Pediatrics cardiology. Ibn Al-Nafis cardiovascular teaching hospital.

*** Medical City, Baghdad Teaching Hospital

Received 24 $4^{\text {th }}$ July 2017, accepted in final 23 $3^{\text {th }}$ Oct 2017

Corresponding to . Ali Mohammed Al Yassin
$\mathrm{S}$ ystemic Hypertension is an important public health challenge in both developing and developed countries, it present in approximately $26 \%$ of the adult population all over the world ${ }^{(1)}$. Such individuals are predisposed to the development of major cardiovascular events. LV dyssynchrony is a difference in the timing or lack of synchrony in contractions of the LV . Large differences in timing of contractions can reduce cardiac efficiency and is correlated with $\mathrm{HF}^{(2)}$. LV systolic and diastolic dyssynchrony are not uncommon in patients with hypertension. Dyssynchrony is associated with increasing incidence of $\mathrm{HF}$, cardiovascular morbidity and mortality ${ }^{(3)}$

systemic hypertension: Hypertension also known as high blood pressure, is a long term medicalcondition in which the blood pressure in the arteries is persistently elevated $^{(4)}$. HT isa major risk factor for stroke and cardiovascular diseases and is associated withsignificant morbidity and mortality(5). There are two types of HT:

Primary (essential) hypertension: - there is no identifiable cause of HT. Thistype tends to develop gradually over many years $^{(6)}$.

Secondary hypertension: - Various conditions and medications can lead to secondary $\mathrm{HT}$, including:Kidney problems,Adrenal gland tumors

Thyroid problems,Congenital cause such as coarctation of aorta ,Certain medications such as contraceptive pills, decongestants, over-the counter pain relievers, cocaine and amphetamines ${ }^{(7)}$. 


\section{Definition of Dyssynchrony:}

Dyssynchrony means differences in the timing of contraction or relaxation between the different myocardial segments, There are different classification of dyssynchrony :

1-mechanical or electrical dyssynchrony.

2- Atrioventricular, interventricular, intraventricular.

3- Systolic or diastolic ${ }^{(8)}$.

Specific Echocardiography Methods to Evaluate CardiacDyssynchrony: ${ }^{(9)}$.

1. Septal-to-posterior wall motion delay (SPWMD).

2. Inter-ventricular mechanical delay (IVMD).

3. Tissue doppler imaging indices:

a. Mechanical dyssynchrony index.

b. Basal septal-to-lateral wall Ts. (T-P max).

4. Systolic dyssynchrony index (SDI-16) (Real time 3D echo)

5- Speckle tracking radial strain..

Markers of dyssynchrony ${ }^{(10)}$ :

1- M-mode septum to posterior delay $>130 \mathrm{~ms}$.

2- Inter-ventricular delay $>40 \mathrm{~ms}$.

3- Dyssynchrony index $>33 \mathrm{~ms}$ by TDI.

4 - Septal to posterior wall delay $>60 \mathrm{~ms}$ by TDI.

5- T-P max $>50 \mathrm{~ms}$ By TDI..

6- Systolic strain (\% delayed contraction $>30$ ).

Aim of the study

1- To assess the LV dyssynchrony in HT patients with normal systolic function by using Tissue dopplerimaging .

2- To find out the associations between the LV dyssynchrony and other global echocardiographic findings like (LA volume index, LV mass index, LV sephericity and LV filling pressure E/E') .

\section{Patients:}

Patients' design :case- control descriptive study.

Setting :Prospective study conducted in Baghdad Teaching Hospital

(cath.unit).

Duration :From 1st of June 2015 to 30th of May 2016.

\section{Inclusion Criteria.}

1- (group 1) normal healthy people (normotensive) (control group ).

2- (group 2) patients with established hypertension of variable duration

and normal QRS duration(<120 msec) (ECG) .

Exclusion criteriawere as follows:

1- Congestive heart failure, $\mathrm{EF}<54 \%$

2-Ischemic Heart Disease with segmental wall motion abnormalities .

3- Evidence of valvular heart disease (regurgitation more than mild or

any degree of stenosis).

4- Pulmonary hypertension.

5- Pericardial disease.

6- Atrial fibrillation .

7- Any cause of secondary HPT such as kidney, adrenal and thyroid

problems ,Coarctation of aorta .

8-patients with hypertrophic cariomayopathy.

\section{Methods}

Questionnaire:Data collection was done using questionnaire which included the personal data (Age ,Gender, Height ,Weight) and clinical Examination Included (chest examination, abdominal examination, BP , PR and JVP ).

ECG was performed for all patients using Schiller device (Schiller AG, Cardiovit CH-6341,Baar, Swiss made) and transthoracic echocardiography (2dimensional and Doppler) study using available equipment (Vivid GE 9) equipped with phased array transducer of $2.5 \mathrm{MHZ}$ with simultaneous ECG tracing.

TDI recordings were obtained in basal and mid-LV segments from 3 apical views.LV measurements were made according to recommendations of the ASE. LeftAtrialvolume, LVmassand LV sphericity index were calculated , LV diastolic function and LV Fillingpressure were also assessed. LV dyssynchrony was assessed by measurements of time intervals from onset of the QRS complex to the peak systolic velocity on the pulsed tissue Doppler waveform (T-P) in the 3 apical views. The maximum T-P was measured as the maximaldifference of T-Pbetween any 2 opposing LV walls. T-Pmax value of $50 \mathrm{msec}$. was selected as the cut point for LV dyssynchrony.

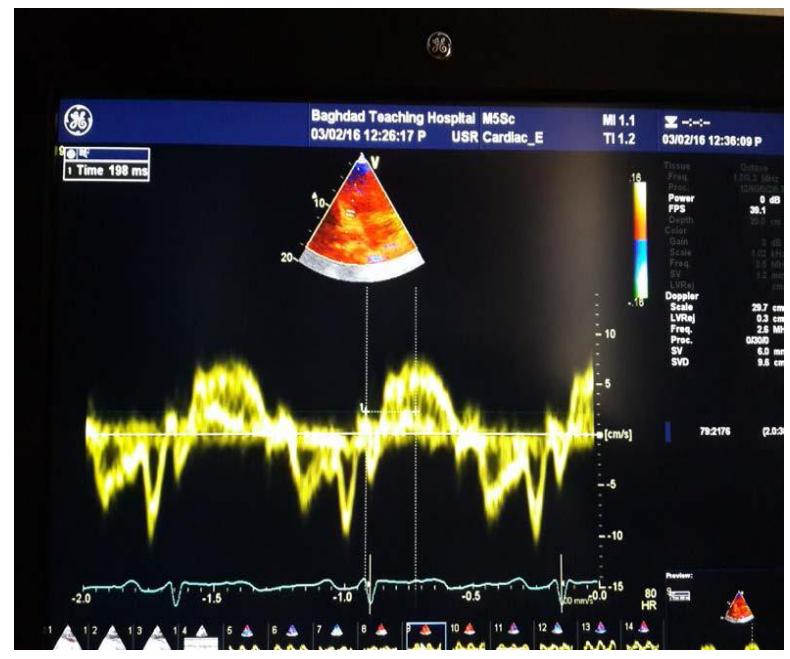

TDI method to measure the T-P value

Statistical analysis was done using computerized statistical software; statistical package for social sciences (SPSS) (version 16).

1- Mean and standard deviation were done for all quantitative continuous variables.

2- Two -Pearson correlations with 2-tailed analysis were used to test associations between continuous data sets (e.g., between LV mass and dyssynchrony, and between LA size and dyssynchrony and others associations). Significant result is considered when $P$-value $<0.05$, and highly significant when $<0.001$, and non-significant when $>0.05$.

Results:The study included 40 age -matched control people, 27 males $(67.5 \%)$ and 13 females $(32.5 \%)$ with a male to female ratio was $1.8: 1$, (group 1) and 
60hypertensive patients, 38 males (63.3\%) and 22 females $(36.7 \%)$ with a male tofemale ratio was $1.7: 1$, (group 2) .Table 1 shows the distribution of studied groups according to their demographic characters as the age of normal (control) group was ranging from (42.4$58 \mathrm{y})$ with mean age of $(50.2 \pm 7.8 \mathrm{y})$ and hypertensive patients wasranging from (48.5-66.5y) with mean age of $(57.5 \pm 9.0 y)$. Mean of BSA incontrol group was (1.89 \pm $0.14)$ which is nearly similar to hypertensive group $(1.92$ \pm 0.23 ) , mean systolic blood pressure in control group was $(110 \pm 10.1 \mathrm{mmHg})$ which is less than that of hypertensive group $(147.4 \pm 22.5 \mathrm{mmHg})$ and theQRS duration in control group was nearly similar to that seen in hypertensivepatients $(84.1 \pm 10.5 \mathrm{msec}),(86.5 \pm 11.7$ msec) respectively.

(Table 1): The distribution of studied groups according to their demographic characters

\begin{tabular}{|c|c|c|}
\hline Demographic character & $\begin{array}{c}\text { NormaL } \\
\text { mean } \pm \text { SD }\end{array}$ & $\begin{array}{c}\text { Hypertensive patient } \\
\text { mean } \mathrm{SD}\end{array}$ \\
\hline $\mathrm{Age}(\mathrm{Y})$ & $50.2 \pm 7.8$ & $57.5 \pm 9.0$ \\
\hline Height $(\mathrm{m})$ & $1.64 \pm 0.41$ & $1.69 \pm 0.11$ \\
\hline BSA (m²) & $1.89 \pm 0.14$ & $1.92 \pm 0.23$ \\
\hline $\begin{array}{c}\text { Systolic blood } \\
\text { pressure (mmHg) }\end{array}$ & $110 \pm 10.1$ & $147.4 \pm 22.5$ \\
\hline $\begin{array}{c}\text { QRS duration(msec) } \\
\text { ECG }\end{array}$ & $84.1 \pm 10.5$ & $86.5 \pm 11.7$ \\
\hline
\end{tabular}

Hypertensive Patients were on a variety of antihypertensive medications including 32 of 60 patients taking 2 drugs (53.3\%) and $28(46.7 \%)$ taking 3 ormore antihypertensive medications.Table 2show the echocardiographic findings in normal and hypertensive patients so we found the mean of LA volume $(\mathrm{ml})$, LA volume index $(\mathrm{ml} / \mathrm{m} 2)$ innormal group was $(29.1 \pm 4.18)$, $(20.4 \pm 3.57)$ respectively this proved to bestatistically significant less than hypertensive group ( $55.9 \pm 9.38$ $\mathrm{ml}), \quad(32.7 \pm 5.18 \mathrm{ml} / \mathrm{m} 2) \quad(p=0.0001)$. The same table shows the mean of LV mass in normal group was (150 \pm 13.4), LV mass index was $(90.4 \pm 6.5)$ both of them significantly lower thanhypertensive group (210.3 \pm $38.43 \mathrm{~g}),(115.1 \pm 7.11 \mathrm{~g} / \mathrm{m} 2)$ respectively $(P=0.0001)$. Mean of LV sphericity index in normal group was $(0.46 \pm$ 0.43 ) whichis more than hypertensive group ( $0.36 \pm$ $0.03)(p=0.0031)$. The mean of LVseptal thickness in normal group was $(0.7 \pm 0.09 \mathrm{~mm})$ which significantly less thanhypertensive group $(13.0 \pm 0.13 \mathrm{~mm})$ ( $P$ $=0.0001)$. The mean EF of normal groupwas nearly similar to hypertensive group $(64 \pm 5.3 \%)(65.1 \pm 4.1 \%)$ respectively ( $P=0.18$ )(not significant). The mean of lateral mitral relaxation velocity $\left(E^{\prime}\right)$ innormal group was significantly higher than hypertensive group (9.8 \pm 1.1$)$, $(7.2 \pm 0.5)$ respectively $(P=0.045)$, mean of LV filling pressure (mitral inflow tomitral relaxation velocity ratio) $\left(E / E^{\prime}\right)$ in normal group was $(9.5 \pm 2.9)$ which issignificantly lower than hypertensive group $(13 \pm 1.1)$ $(P=0.0001)$. Finally themean of T_Pmax (marker of dyssynchrony) in normal group was (30.6 $\pm 4.75 \mathrm{msec})$ which is whithin normal range and significantly lower than hypertensive group $(56.5 \pm 25 \mathrm{msec})(P=0.001)$. The LV dyssynchrony in hypertensive patients (T-P max $>50 \mathrm{msec}$ ) (ranging from 51 to $83 \mathrm{msec}$ ) was identified in 20 of 60 patients (33.3\%)of hypertensive patients.

(Table 2) : Echocardiographic findings in hypertensive and control groups.

\begin{tabular}{|c|c|c|c|}
\hline Echo findings & $\begin{array}{c}\text { Normal (control) } \\
\text { Mean } \pm S D\end{array}$ & $\begin{array}{c}\text { Hypertensive patient } \\
\text { Mean } \pm S D\end{array}$ & P-Value \\
\hline LA volume (ml) & $29.1 \pm 4.18$ & $55.9 \pm 9.38$ & 0.0001 \\
\hline $\begin{array}{l}\text { LA volume index } \\
\left(\mathrm{ml} / \mathrm{m}^{2}\right)\end{array}$ & $20.4 \pm 3.57$ & $32.7 \pm 5.18$ & 0.0001 \\
\hline LV mass $(\mathrm{g})$ & $150 \pm 13.4$ & $210.3 \pm 38.43$ & 0.0001 \\
\hline $\begin{array}{c}\text { LV mass index } \\
\left(\mathrm{g} / \mathrm{m}^{2}\right)\end{array}$ & $90.4 \pm 6.5$ & $115.1 \pm 7.11$ & 0.0001 \\
\hline Sphericity index & $0.46 \pm 0.43$ & $0.36 \pm 0.03$ & 0.0031 \\
\hline $\begin{array}{c}\text { LV septal } \\
\text { thickness (mm) }\end{array}$ & $0.7 \pm 0.09$ & $13.0 \pm 0.13$ & 0.0001 \\
\hline $\mathrm{EF} \%$ & $64 \pm 5.3$ & $65.1 \pm 4.1$ & 0.18 \\
\hline $\mathrm{E}^{\prime}(\mathrm{cm} / \mathrm{s})$ & $9.8 \pm 1.1$ & $7.2 \pm 0.5$ & 0.045 \\
\hline $\mathrm{E} / \mathrm{E}^{\prime}$ & $9.5 \pm 2.9$ & $13 \pm 1.1$ & 0.0002 \\
\hline $\begin{array}{c}\text { TP-max to } \\
\text { systole (msec) }\end{array}$ & $30.6 \pm 4.75$ & $56.5 \pm 25.0$ & 0.0001 \\
\hline
\end{tabular}

The T-P max had no significant association with age $(\mathrm{p}=$ $0.2)$ and $B S A(P=0.4)$ ( Table 6).

Table 4 shows the correlation of LV dyssynchrony which assessed by T-Pmaxwas significantly associated with LA volume $(r=0.63, \mathrm{p}=0.001)$ or LA volumeindex $(r=$ $0.61, p=0.001)$ i.e greater LVdyssynchrony was observed withincreasing LA volume or index. A similar relationship was observed between TPmax and LV mass $(r=0.64, p=0.001)$ or LV mass index $(r=0.52, p=$ $0.001)$.LV dyssynchrony was significantly associated and positively correlated withLVsphericity index $(r=0.5$, 
$\mathrm{p}=0.003)$.The T-P $\max$ had significant negativecorrelation with $\left(E^{\prime}\right)$ velocity $(r=-0.7, p=$ 0.001 ) and finally the T-P max hadsignificant association with LV filling pressure $\left(E / E^{\prime}\right)(r=0.6, p=0.001)$.

(Table 3) :pearson correlations of LV Systolic dyssynchrony with Age and BSA

\begin{tabular}{|c|c|c|}
\hline Varaible & $\begin{array}{c}\text { Pearson } \\
\text { correlation (r) }\end{array}$ & $\mathrm{p}$ - value \\
\hline Age & +0.3 & 0.2 \\
\hline BSA & -0.07 & 0.4 \\
\hline
\end{tabular}

(Table 4) :pearson correlations of LV Systolic dyssynchrony with Echo.findings data.

\begin{tabular}{|c|c|c|}
\hline $\begin{array}{c}\text { LV } \\
\text { dyssynchrony } \\
\text { (T-P max) }\end{array}$ & $\begin{array}{c}\text { Pearson } \\
\text { correlation } \\
(\mathrm{r})\end{array}$ & P_value \\
\hline LA volume & 0.63 & 0.001 \\
\hline $\begin{array}{c}\text { LA volume } \\
\text { index }\end{array}$ & 0.61 & 0.0001 \\
\hline LV mass & 0.64 & 0.001 \\
\hline LV mass index & 0.52 & 0.001 \\
\hline $\begin{array}{c}\text { Sphericity } \\
\text { index }\end{array}$ & 0.5 & 0.003 \\
\hline E' velocity & -0.7 & 0.001 \\
\hline E/E & 0.6 & 0.001 \\
\hline EF\% & -0.08 & 0.4 \\
\hline
\end{tabular}

Figure 1 show the diagram of positive correlation between LV dyssynchronyand LA volume index which mean greater LV dyssynchrony was observed withincreasing LA volume index $(r=0.61, \mathrm{p}=0.001)$.

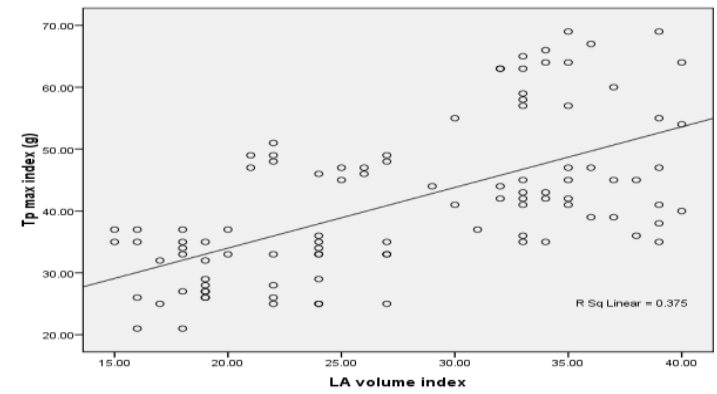

(Figure 1) : correlation between LV dyssynchrony ( T-P max) and LA volume index
Figure 2 show the diagram of significant positive correlation between LVdyssynchrony and LV mass index $(r=0.52, p=0.001)$. Figure 3 show the diagram of positive correlation between LV dyssynchronyand LV sphericity index $(r=0.5, \mathrm{p}=0.003)$.

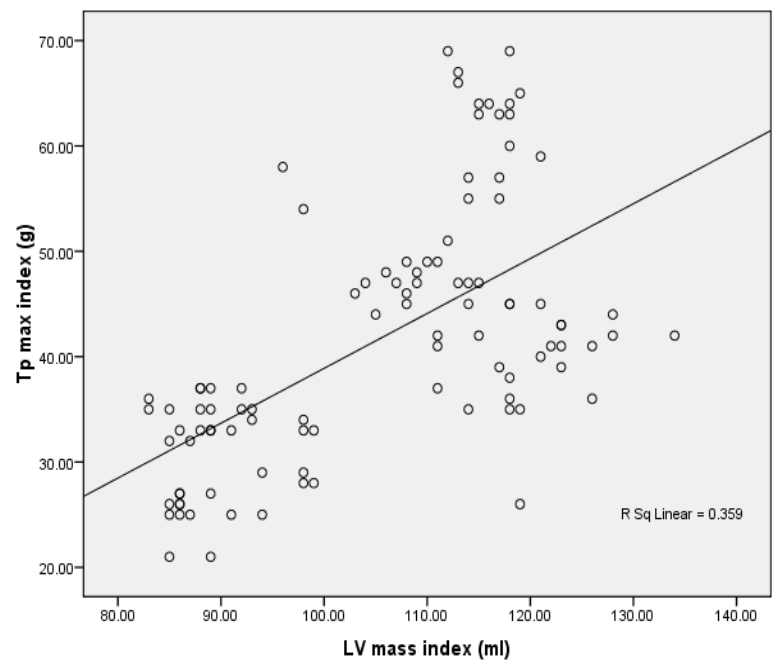

Figure 2) : correlation between LV dyssynchrony ( T-P max) and LV massindex

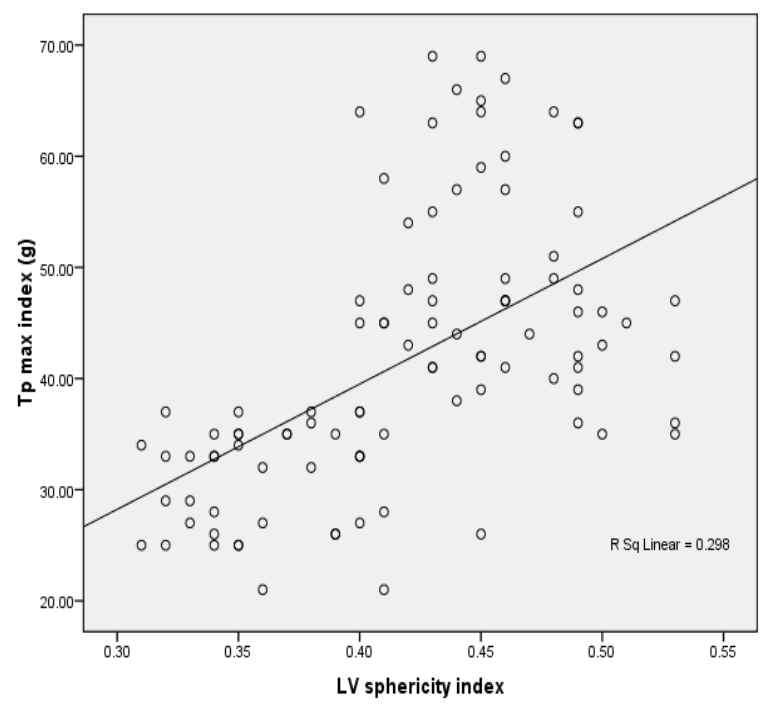

(Figure 3) : correlation between LV dyssynchrony ( T-P max) and LV sphericityindex

Discussion: Age of the patients was ranging from (48.5$66.5 y$ ) that show no relationwith LV systolic dyssynchrony ( $p$-value $=0.2$ ) which is similar to that foundby Benjamin Yang et al ${ }^{(11)}$.

Left ventricular systolic dyssynchrony ( T-Pmax $>50$ msec) was identified in20 patients (33.3\%) in the hypertensive group which is similar to that reportedby 
Wang et al $(33 \%)^{(12)}$ and less than that reported by $\mathrm{Yu}$ et al $(39 \%){ }^{(13)}$ andBenjamin Yang et al $(41 \%){ }^{(11)}$. Hypertensive patients show higher LA volume index $(32.7 \pm 5.18 \mathrm{ml} / \mathrm{m} 2)(p$-value $=0.0001)$ and LV mass index $(115 \pm 7.11 \mathrm{~g} / \mathrm{m} 2)(p-v a l u e=0.0001)$ than normalcontrol group. LV dyssynchrony was strongly associated with $L A$ volume index $(P$-value $=0.0001)$ and LV mass index $(P$-value $=0.001)$, these findings are similarto that reported by McKee PA et al ${ }^{(14)}$. The LV dyssynchrony among suchpatients is related to the magnitude of LV hypertrophy and LA size. Thissignificant relationship provide further insight into the effects of hypertension onLV function and the potential mechanism for the development of clinical HF inpatients with normal systolic function. HT cause LV hypertrophy, increased LVfilling pressure and ultimately increased LA volume. The latter has beendemonstrated to have important prognostic implications for cardiovascular events ${ }^{(15,16)}$. LV systolic dyssynchrony was significantly associated with LV Sphericityindex, the T-P max showed negative correlation to LV sphericity $(p=0.003$ ) which is similar to that reported by Benjamin Yang et al (11). LV remodeling(abnormal LV sphericity) parallels thedevelopment of hypertrophyand changes in LA size. These changes are accompanied by changes in ventricularsynchrony that may precede the development of clinical heart failure ${ }^{(17)}$. we found that LV dyssynchrony was considered as important cause in developing the mechanisms of LV remodeling which is the same result found byYuda $S$ et al ${ }^{(17)}$. The T-P max had significant negativecorrelation with $\left(E^{\prime}\right)$ velocity (Pvalue $=0.001)$ i.e greater LV dyssynchrony was strongly associated withlowerearly diastolic relaxation assessed by $E^{\prime}$ which is similar to that found by OpdahlA. et al (P-value $=0.0001)^{(18)}$.T-P max had significant association with LV filling pressure (E/E') (Pvalue $=0.001)$ Which is nearly similar to that reported by Chang et al $(P$-value $=0.0005){ }^{(19)}$.

\section{Conclusion:}

1- LV dyssynchrony is frequent among hypertensive patients with normal LVsystolic function .

2- The LV dyssynchrony is significantly related to LA volume, LV mass, LVremodeling and LV filling pressure.

\section{Recommendation:}

1- Follow-up study will be necessary to determine whether LV dyssynchronyin hypertensive patients is associated with the subsequent development ofHF and to determine patients who may benefit from more intensivehypertension control at an earlier stage in their disease process.

2- Another imaging methods such as Strain, strain rate and speckle tracking inaddition to TDI consider addifrent methods used for evaluation of LVdyssynchrony.

\section{References}

1. Patricia MK, Megan Whelton, Kristi Reynolds, Paul $\mathrm{KW}$, Jiang $\mathrm{H}$, et al. Worldwide prevalence of hypertension: a systematic review. Journal of Hypertension,2004; 22: 11-19.

2. Bank AJ, Kelly AS Tissue Doppler imaging and left ventricular dyssynchrony in heart failure. J Fail, 2006;12:154-162.

3. SherifF Mechanical Dyssynchrony in Congestive Heart Failure Diagnostic and Therapeutic Implications. J Am CollCardiol ,2008;51:18-22.

4. Dan L.L Dennis L.K, Larry J,Anthong S.F, Stephen L.H, Joseph L.:Harrison principles of internal medicine, 18th edition,McGraw-Hill companies, Inc,2012, volume1,pp 247 .

5. Cortigiani L, Bigi R, Landi P, Bovenzi F, Picano E, Sicari R. Prognostic implication of stress echocardiography in 6214 hypertensive and 5328 normotensive patients. Eur Heart J. 2011; 32 1509-1518.

6. Kasner M, Westermann D, Lopez B, et al. Diastolic tissue Doppler indexes correlate with the degree of collagen expression and cross-linking in heart failure and normal ejection fraction. J Am CollCardiol. 2011; 57: 977-985.

7. Fici F, Ural D, Tayfun S, et al. Left ventricular diastolic dysfunction in newly diagnosed untreated hypertensive patients. Blood Press,2012; 21: 331 337.

8. Grines $\mathrm{CL}$, Bashore TM, Boudoulas $\mathrm{H}$, Olson S, Shafer P, Wooley

CF.FunctionL abnormalities in isolated left bundle branch block. The effect of interventricular asynchrony. Circulation 1989;79:845-853.

9. GorcsanJr, Abraham T, Agler DA, et al. Echocardiography for cardiac resynchronization therapy: recommendations for performance and reporting - a report from the American Society of Echocardiography Dyssynchrony Writing Group endorsed by the Heart Rhythm Society. J Am SocEchocardiogr 2008;21(3): 191-213 .

10. Yu CM, Fung JW, Zhang Q, et al. Tissue Doppler imaging is superior to strain rate imaging and postsystolic shortening on the prediction of reverse remodeling in both ischemic and nonischemic heart failure after cardiac resynchronization therapy. Circulation 2004;110(1):66-73.

11. Benjamin Y, Dennis C, Fermon J, Millan A, Jannet $\mathrm{FL}$, et al .Left Ventricular Dyssynchrony in 
Hypertensive Patients Without Congestive Heart Failure ClinCardiol , 2008;12: 597-601.

12. Wang J, Kurrelmeyer KM, Torre-Amione G, Nagueh SF: Systolic and diastolic dyssynchrony in patients with diastolic heart failure $\mathrm{n}$ and the effect of medical therapy. J Am CollCardio/2007;49:88-96.

13. Yu C-M, Zhang Q, Yip GWD, Lee P-W, Kum LCC, et al.: Diastolic and systolic asynchrony in patients with diastolic heart failure. $J 8 A m$ CollCardiol2007;49:97-105

14. McKee PA, Castelli WP, McNamara PM, Kannel WB: The natura history of congestive heart failure: the Framingham study. $N$ Engl $J$ Med 1971;285:1441-1446.

15. Tsang TS, Barnes ME, Gersh BJ, Bailey KR, Seward JB: Left atrial volume as a morphophysiologic expression of left ventricular diastolic dysfunction and relation to cardiovascular risk burden Am J Cardiol2002;90:1284-1289.
16. Gottdiener JS, Kitzman DW, Aurigemma GP, Arnold AM,Manolio TA: Left atrial volume, geometry, and function in systolic and diastolic heart failure of persons 65 years of age (theCardiovascular Health Study). Am J Cardiol 2006;97:83-89

17. Yuda S, Short L, Leano R, Marwick TH. Myocardial abnormalities in

hypertensive patients with normal and abnormal left ventricular filling: a study of ultrasound tissue characterization and strain. ClinSci (Lond) 2002;103:283-93.

18. Opdahl A, Remme EW, Helle-Valle T, Lyseggen E, Vartdal T, Pettersen E, Edvardsen T, Smiseth OA. Determinants of left ventricular early-diastolic lengthening velocity: independent contributions from left ventricular relaxation, restoring forces, and lengthening load. Circulation 2009;119:25782586

19. Chang SA,Kim DH patientKim,SohanDW.Oh BH et al.Left ventricular systolic and diastolic dyssynchrony in asymptomatic hypertensive.JamSocEchocardiogr 2009;22:33742. 